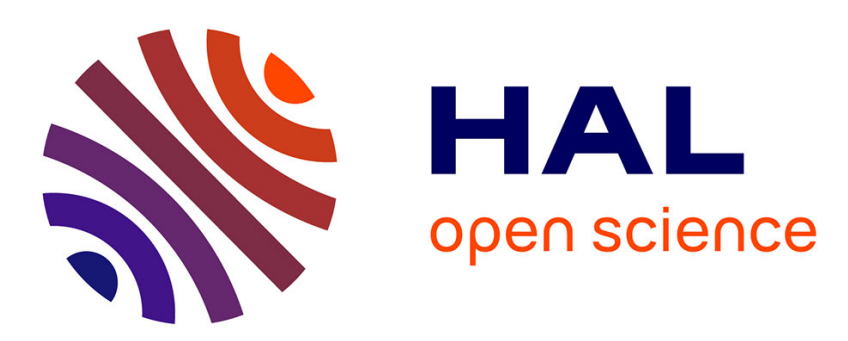

\title{
Experimental hydrodynamic study of valve trays
}

R. Brahem, A. Royon-Lebeaud, Dominique Legendre, M. Moreaud, L. Duval

\section{To cite this version:}

R. Brahem, A. Royon-Lebeaud, Dominique Legendre, M. Moreaud, L. Duval. Experimental hydrodynamic study of valve trays. Chemical Engineering Science, 2013, 100, pp.23-32. 10.1016/j.ces.2013.03.030 . hal-01330605

\section{HAL Id: hal-01330605 https://hal-ifp.archives-ouvertes.fr/hal-01330605}

Submitted on 6 Jan 2020

HAL is a multi-disciplinary open access archive for the deposit and dissemination of scientific research documents, whether they are published or not. The documents may come from teaching and research institutions in France or abroad, or from public or private research centers.
L'archive ouverte pluridisciplinaire HAL, est destinée au dépôt et à la diffusion de documents scientifiques de niveau recherche, publiés ou non, émanant des établissements d'enseignement et de recherche français ou étrangers, des laboratoires publics ou privés. 


\title{
Experimental hydrodynamic study of valve trays
}

\author{
$\underline{\text { R. Brahem }}{ }^{\mathrm{a} *}$, A. Royon-Lebeaud ${ }^{\mathrm{a}}$, D. Legendre ${ }^{\mathrm{b}}$, M. Moreaud ${ }^{\mathrm{a}}$ and L. Duval ${ }^{\mathrm{c}}$ \\ ${ }^{a}$ IFP Energies nouvelles, Rond-point de l'échangeur de Solaize, BP 3 - 69360 Solaize - France \\ ${ }^{\mathrm{b}}$ IMFT, 1 Allée du Professeur Camille Soula, 31400 Toulouse- France \\ 'IFP Energies nouvelles, 1 et 4, avenue de Bois-Préau 92852 Rueil-Malmaison Cedex — France \\ ${ }^{*}$ Corresponding author \\ E-mail address : $\underline{\text { rim.brahem@ifpen.fr }}$ \\ Telephone : +33437702000 \\ Fax : +33437702008
}

\begin{abstract}
The most widely used sour gas sweetening process consists of treating the acid gas with aqueous amines solutions. Mass transfer between gas and liquid phases takes place in absorption columns where valve trays are commonly used as contactor devices. Design of industrial columns relies on empirical correlations developed on pilot units. Nevertheless, available experimental data and correlations on valve trays are scarce in comparison with works done on sieve trays. Optimal column design is hard to achieve because correlations provided in literature present large discrepancies. More thorough studies dedicated to valve trays are needed to develop reliable design correlations.

The present hydrodynamic study was carried out on a Plexiglas $1.26 \mathrm{~m}$ per $0.1905 \mathrm{~m}$ absorption column containing four V-4 Glitsch valve trays. Water/air system was used at atmospheric pressure and ambient temperature. Liquid rate per weir unit length was varied between $3.210^{-3} \mathrm{~m}^{3} .(\mathrm{m} . \mathrm{s})^{-1}$ and
\end{abstract} $24.310^{-3} \mathrm{~m}^{3} \cdot(\mathrm{m} . \mathrm{s})^{-1}$ and the kinetic gas factor between 0 and $3.5 \mathrm{~Pa}^{0.5}$. 
The following hydrodynamic parameters were determined: tray pressure drop, valves pressure drop, clear liquid height, mean emulsion height and liquid mean hold up on the tray. Correlations for clear liquid height, liquid mean hold up and emulsion height are proposed.

Emulsion profiles characterisation was possible due to video records post-processing. Four different behaviours are identified for emulsion profiles according to liquid and gas velocities.

Significant behaviour changes on the hydrodynamic parameters allowed the identification of 3 system limits: dumping, weeping and pre-flooding. Correlations are proposed for these limits and an operational diagram is presented.

Keywords: Absorption; Hydrodynamics; Multiphase flow; Scale up; Valve trays; Emulsion height profiles. 


\section{Nomenclature}

\begin{tabular}{|c|c|c|}
\hline$A_{a}$ & $\mathrm{~m}^{2}$ & Active or bubbling area \\
\hline$A_{h}$ & $\mathrm{~m}^{2}$ & Perforated area \\
\hline$A_{T}$ & $\mathrm{~m}^{2}$ & Total columncross area \\
\hline$d_{h}$ & $\mathrm{~m}$ & Hole diameter \\
\hline$d_{V}$ & $\mathrm{~m}$ & Valve diameter \\
\hline $\mathrm{Fa}$ & $\mathrm{Pa}^{0.5}$ & Kinetic gas factor based on velocity toward active area \\
\hline$g$ & $\mathrm{~m} \cdot \mathrm{s}^{-2}$ & Gravity acceleration \\
\hline$h_{F e}$ & $\mathrm{~m}$ & Emulsion height on the tray \\
\hline$h_{L}$ & $\mathrm{~m}$ & Clear liquid height on the tray \\
\hline$h_{w}$ & $\mathrm{~m}$ & Exit weir height \\
\hline$L$ & $\mathrm{~m}^{3} \cdot \mathrm{m} . . \mathrm{s}^{-1}$ & Liquid loading or liquid flow rate per unit weir length \\
\hline$L_{D}$ & $\mathrm{~m}$ & Downcomer length \\
\hline$L_{P}$ & $\mathrm{~m}$ & Length flow path \\
\hline$L_{T}$ & $\mathrm{~m}$ & Total column length \\
\hline$L_{w}$ & $\mathrm{~m}$ & Exit weir length \\
\hline$P$ & $\mathrm{~Pa}$ & Pressure \\
\hline$Q_{G}$ & $\mathrm{~m}^{3} \cdot \mathrm{s}^{-1}$ & Gas flow rate \\
\hline$Q_{L}$ & & Liquid flow rate \\
\hline$T_{s}$ & $\mathrm{~m}$ & Tray spacing \\
\hline$U_{G, a}$ & $\mathrm{~m} \cdot \mathrm{s}^{-1}$ & Gas velocity toward active area \\
\hline$U_{G, h}$ & $\mathrm{~m} \cdot \mathrm{s}^{-1}$ & Gas velocity toward perforated area \\
\hline$U_{L}$ & $\mathrm{~m} \cdot \mathrm{s}^{-1}$ & Liquid velocity defined in relation (11) \\
\hline$U_{L, a}$ & $\mathrm{~m} . \mathrm{s}^{-1}$ & Liquid velocity toward active area \\
\hline \multicolumn{3}{|c|}{ Dimensionless numbers } \\
\hline$C_{D}$ & - & Friction coefficient \\
\hline$F P^{\prime}$ & - & $\begin{array}{l}\text { Flow parameter, represents the square root of the ration between liquid } \\
\text { inertia and gas inertia }\end{array}$ \\
\hline $\mathrm{Fr}$ & - & $\begin{array}{l}\text { Froude number opposing gas inertia toward active area to liquid weight on } \\
\text { the tray }\end{array}$ \\
\hline$F r_{h}$ & - & Froude number using gas velocity toward perforated area \\
\hline \multicolumn{3}{|c|}{ Greek letters } \\
\hline$\alpha_{L}$ & - & Mean liquid hold up on tray \\
\hline$\Delta P_{\text {Dry }}$ & $\mathrm{Pa}$ & Valves (or tray) pressure drop measured in absence on liquid flow \\
\hline$\Delta P_{\text {Emulsion }}$ & $\mathrm{Pa}$ & Pressure drop due to emulsion on tray \\
\hline$\Delta P_{\text {Tray }}$ & $\mathrm{Pa}$ & Tray pressure drop \\
\hline$\Delta P_{\text {Valves }}$ & $\mathrm{Pa}$ & Valves pressure drop measured in presence on liquid flow \\
\hline$\mu_{G / L}$ & Pa.s & Gas/liquid viscosity \\
\hline$\rho_{G}$ & $\mathrm{~kg} \cdot \mathrm{m}^{-3}$ & Gas density \\
\hline$\rho_{L}$ & $\mathrm{~kg} \cdot \mathrm{m}^{-3}$ & Liquid density \\
\hline$\psi$ & $\mathrm{m}$ & flow ratio opposing liquid loading time square root liquid density and \\
\hline & & kinetic gas factor \\
\hline
\end{tabular}




\section{Introduction}

Valve trays are commonly used as internals in acid gas sweetening process. In this process natural gas, highly charged with acid compounds (mainly carbonic gas and hydrogen sulphide), is treated using aqueous amines solutions.

Industrial units design involves the determination of two main parameters which are column diameter and height. The diameter is controlled by two phase flow hydrodynamic behaviour (weeping, flooding). Total column height is controlled by mass transfer parameters.

Because of flow complexity on the tray, the design of absorption columns still relies on empirical correlations developed on pilot units. Available correlations in the literature present large discrepancies in shape, results, and choice of influent parameters because of their dependence to the pilot units. In addition, most experimental studies are done on sieve trays and few data is available on valve trays. For these reasons, extrapolation to industrial scale is not yet optimal.

Experimental works on hydrodynamic parameters are done in order to set hydrodynamic diagrams which are useful for diameter determination. These diagrams are equally important for total column height definition because certain hydrodynamic parameters are involved in the determination and prediction of mass transfer coefficients (e.g.: clear liquid height $h_{L c}$, liquid hold up $\alpha_{\mathrm{L}} \ldots$ ).

System limits determination is important for column operability. At a fixed liquid rate $Q_{L}$, two main gas velocity thresholds exist: weeping and flooding. Both limits have to be well known before designing industrial units.

Weeping is the lower limit and it corresponds to a part of liquid flowing down through the plate perforations. Excessive weeping causes an important decrease of tray efficiency. Existing theoretical and semi-theoretical studies upon weeping from single orifice are well synthesised by (Lockett 1986). The different models point out the importance of hole Froude number $\mathrm{Fr}_{\mathrm{h}}$ representing the ratio between gas inertia and liquid weight on the tray (see Equation (1)). 
$F r_{h}=\frac{\rho_{G} U_{G, h}{ }^{2}}{g h_{L} \rho_{L}}$

Several studies use this parameter to predict perforated trays weeping ((Mayfield et al. 1952); (Wijn, 1998)). Since these correlations take into account only the static liquid weight they imply an increase of the weeping limit with increasing liquid load $L$. However, some studies stating the decrease of weeping with liquid load exist ((Fair 1997); (Qian et al. 2006)).

The upper limit of column operability is the flooding point. It corresponds to the entrainment of part of the liquid of the tray to an upper tray. As described by (Kister et al. 2007) and (Lockett 1986), jet flooding limit is admitted to increase very slightly with increasing liquid load. A maximum is reached indicating the transition to downcomer flooding. This second flooding limit decreases sharply with liquid load. But though flood limit behaviour is commonly admitted correlations available in the literature are different in shape and results. For instance in Glitsch (Glitch, Inc., 1974) and Koch (Koch Engineering Co. 1982) correlations liquid load $L$ (see (2)) is used whereas in Nutter (Nutter Engineering Co. 1976) correlation it is liquid velocity toward active area $U_{L a}$ (see (3)) that is considered and for (Zuiderweg 1982) the controlling factor is flow parameter with the same area considered for liquid and gas velocities $F P^{\prime}$ (see (4)).

$$
\begin{aligned}
& L=\frac{Q_{L}}{L_{W}} \\
& U_{L a}=\frac{Q_{L}}{A_{a}} \\
& F P^{\prime}=\frac{Q_{L}}{Q_{G}} \sqrt{\frac{\rho_{L}}{\rho_{G}}}
\end{aligned}
$$

The two phase flow on the tray is mainly described as a homogeneous flow. Francis equation type correlations for emulsion height over exit weir are thus used ((Colwell 1981); (Bennett et al. 1983); (El-Azrak 1988); (Liang et al. 2008)). 
$h_{L c}=\alpha_{L} h_{F e}=\alpha_{L} h_{w}+C_{D}\left(\frac{\alpha_{L} L^{2}}{g}\right)^{1 / 3}$

Where $h_{L c}$ is the clear liquid height, $\alpha_{L}$ is the liquid hold up, $h_{F e}$ is the emulsion height and $C_{D}$ is an empirical friction coefficient that differs according to experimental studies.

Influence of gas flow rate on clear liquid height is entirely projected in liquid hold up $\alpha_{\mathrm{L}}$. Most usually, the latter parameter is determined using the ratio between clear liquid height and emulsion height.

$\alpha_{L}=\frac{h_{L c}}{h_{F e}}$

The trajectory model is the other widely used description model for two phase flow on the tray. This model accords more importance to liquid-gas interaction and thus highlights the importance of flow ratio:

$$
\psi=\frac{L}{U_{G, a}} \sqrt{\frac{\rho_{L}}{\rho_{G}}}
$$

Where $\mathrm{U}_{\mathrm{G}, \mathrm{a}}$ is the gas velocity per active area.

Available correlations usually use this parameter to describe hydrodynamics on valve trays ((Dhulesia, 1984); (Mustafa \& Békássy-Molnár 1997))

This work aims at providing more experimental data on valve trays and better understanding flow behaviour for such devices. Experimental set up and methods are first described. A part is dedicated to video post-processing which allowed measurements of emulsion height profiles. Second, results of tray pressure drop $\Delta P_{\text {Tray }}$, valves pressure drop $\Delta P_{\text {Valves, }}$ clear liquid height $h_{L c}$, emulsion profiles $h_{F e}$, and liquid hold up $\alpha_{L}$ are presented. Comparison to literature is made and correlations are proposed for these different hydrodynamic parameters. Changes in hydrodynamic behaviour are highlighted. Last, operating limits, namely dumping weeping and pre-flooding, are localised according to the observed hydrodynamic changes. Correlations and hydrodynamic diagram are proposed for these system limits. 


\section{Methods and materials}

\subsection{Experimental set up}

The experimental set up used is a Plexiglas rectangular column of $1.26 \mathrm{~m}$ in length and $0.1905 \mathrm{~m}$ in width operated at atmospheric pressure and ambient temperature. Four Glitsch V-4 valve trays are installed in the column with a tray spacing of $0.455 \mathrm{~m}$ (more details are reported in Table 1). Air/water system is used.

Liquid is stored in two communicating tanks of $1200 \mathrm{~m}^{3}$ total volume and it circulates in a closed loop. Gas is supplied by an internal network and enters at the bottom of the column with no specific distributing device.

A grid demister is placed at the column top to prevent any liquid entrainment with gas flow and a separator is set after the column to collect liquid droplets in case of excessive entrainment (Figure 1). Liquid rate was varied from $2.2 \mathrm{~m}^{3} / \mathrm{h}$ to $16.7 \mathrm{~m}^{3} / \mathrm{h}$ which means in term of liquid flow rate per unit weir length between 3.2 and $24.310^{-3} \mathrm{~m}^{3} / \mathrm{m} . \mathrm{s}$. Gas flow rate was varied from 0 to $2100 \mathrm{~m}^{3} / \mathrm{h}$ which in terms of kinetic factor $F a$ (see (8)), which represents the root square of gas inertia, represents a variation between 0 and $3.5 \mathrm{~Pa}^{0.5}$.

$$
F a=\sqrt{\rho_{G} U_{G, a}^{2}}
$$


Table 1: Geometrical characteristics of the column

\begin{tabular}{|c|c|}
\hline \multicolumn{2}{|l|}{ Tray characteristics } \\
\hline$L_{T}(\mathrm{~m})$ & 1.26 \\
\hline$L_{w}(\mathrm{~m})$ & 0.1905 \\
\hline$L_{P}(\mathrm{~m})$ & 0.96 \\
\hline$L_{D}(\mathrm{~m})$ & 0.15 \\
\hline $\mathrm{A}_{\mathrm{T}}\left(\mathrm{m}^{2}\right)$ & 0.24 \\
\hline$A_{a}\left(\mathrm{~m}^{2}\right)$ & 0.18 \\
\hline$A_{h}\left(\mathrm{~m}^{2}\right)$ & 0.032 \\
\hline$h_{w}(\mathrm{~m})$ & 0.065 \\
\hline$L_{w}(\mathrm{~m})$ & 0.1905 \\
\hline Trays number & 4 \\
\hline$T_{s}(\mathrm{~m})$ & 0.455 \\
\hline Valve characteristics & \\
\hline & V4 \\
\hline 1уре & GLITSCH \\
\hline Wweight (kg) & 0,025 \\
\hline Valves/ tray & 27 \\
\hline Minimum valve lift & $0.001 \mathrm{~m}$ \\
\hline Maximum valve lift & $0.009 \mathrm{~m}$ \\
\hline$d_{V}$ & $0.0475 \mathrm{~m}$ \\
\hline$d_{h}$ & $0.039 \mathrm{~m}$ \\
\hline
\end{tabular}


Table 2 : Geometrical characteristics of pilots columns used in reference works

\begin{tabular}{|c|c|c|c|c|c|c|}
\hline \multirow{4}{*}{ Reference } & \multirow{4}{*}{ This work } & \multicolumn{5}{|c|}{ (Mustafa \& } \\
\hline & & (Dhulesia & (Fasesan & Békássy- & (El-Azrak & Verhoeye \\
\hline & & 1984) & 1987) & Molnár & 1988) & 1076) \\
\hline & & & & 1997) & & \\
\hline column & rectangular & rectangular & circular & circular & circular 0.45 & circular \\
\hline dimension & $1.26 \mathrm{~m} * 0.1905 \mathrm{~m}$ & $1.2 \mathrm{~m} * 0.61 \mathrm{~m}$ & $0.63 \mathrm{~m}$ & $0.4 \mathrm{~m}$ & $\mathrm{~m}$ & $0.3 \mathrm{~m}$ \\
\hline$A_{a}\left(\mathbf{m}^{2}\right)$ & 0.183 & 0.559 & 0.237 & 0.098 & 0.084 & 0.063 \\
\hline$A_{h} / A_{a}(\%)$ & 17.6 & 19.5 & 14.3 & 18.5 & 11.9 & 14 \\
\hline valve type & GlitschV-4 & GlitschV-1 & KochT & Nutter & GlitschV-4 & GlitschV-1 \\
\hline $\boldsymbol{h}_{w}(\mathbf{m m})$ & 65 & $50 / 75$ & 50.8 & 50 & $29 / 42 / 72$ & $4.5 / 6 / 7.5 / 9$ \\
\hline
\end{tabular}

\subsection{Measurements}

\subsubsection{Pressure drops}

Both total tray pressure drop $\left(\Delta P_{\text {Tray }}\right)$ and emulsion pressure drop $\left(\Delta P_{\text {Emulsion }}\right)$ were measured. These measurements were made using Rosemount manometers. The pressure connection branches are large enough to neglect capillary effect.

For tray pressure drop $\Delta P_{\text {Tray }}$, the total pressure loss over three trays was measured. Considered $\Delta P_{\text {Tray }}$ is the mean value of the 3 trays pressure loss. Emulsion pressure drop was measured at four different positions on the tray (e1 to e4) as shown in Figure 1. The considered $\Delta P_{\text {Emulsion }}$ is the mean of these four measurements.

Valves pressure drop $\Delta P_{\text {Valves }}$ is due to gas flowing through the valves. It was deducted from the two previous pressure drops by subtracting $\Delta P_{\text {Emulsion }}$ from $\Delta P_{\text {Tray }}$. 
In absence of liquid flow, valves pressure drop is supposed to be equal to tray pressure loss and is called dry pressure drop $\Delta P_{D r y}$.

Pressure connections are slightly elevated from bottom of the tray $(2 \mathrm{~cm})$. This elevation implies that valves pressure drop includes a part of liquid weight. This means that the emulsion pressure drop is slightly under estimated. The error implied by pressure connection elevation is at maximum about 1 mbar.

Emulsion pressure drop can be used to determine clear liquid height $h_{L c}$ as follows:

$h_{L c}=\frac{\Delta P_{\text {Emulsion }}}{\rho_{L} g}$

Emulsion pressure drop is divided into 3 contributions: liquid weight, gas acceleration pressure drop and liquid viscosity effect. Inside water-air emulsion, gas acceleration is considered negligible as well as the effect of liquid viscosity. Thus emulsion pressure drop can be used to evaluate clear liquid height. 


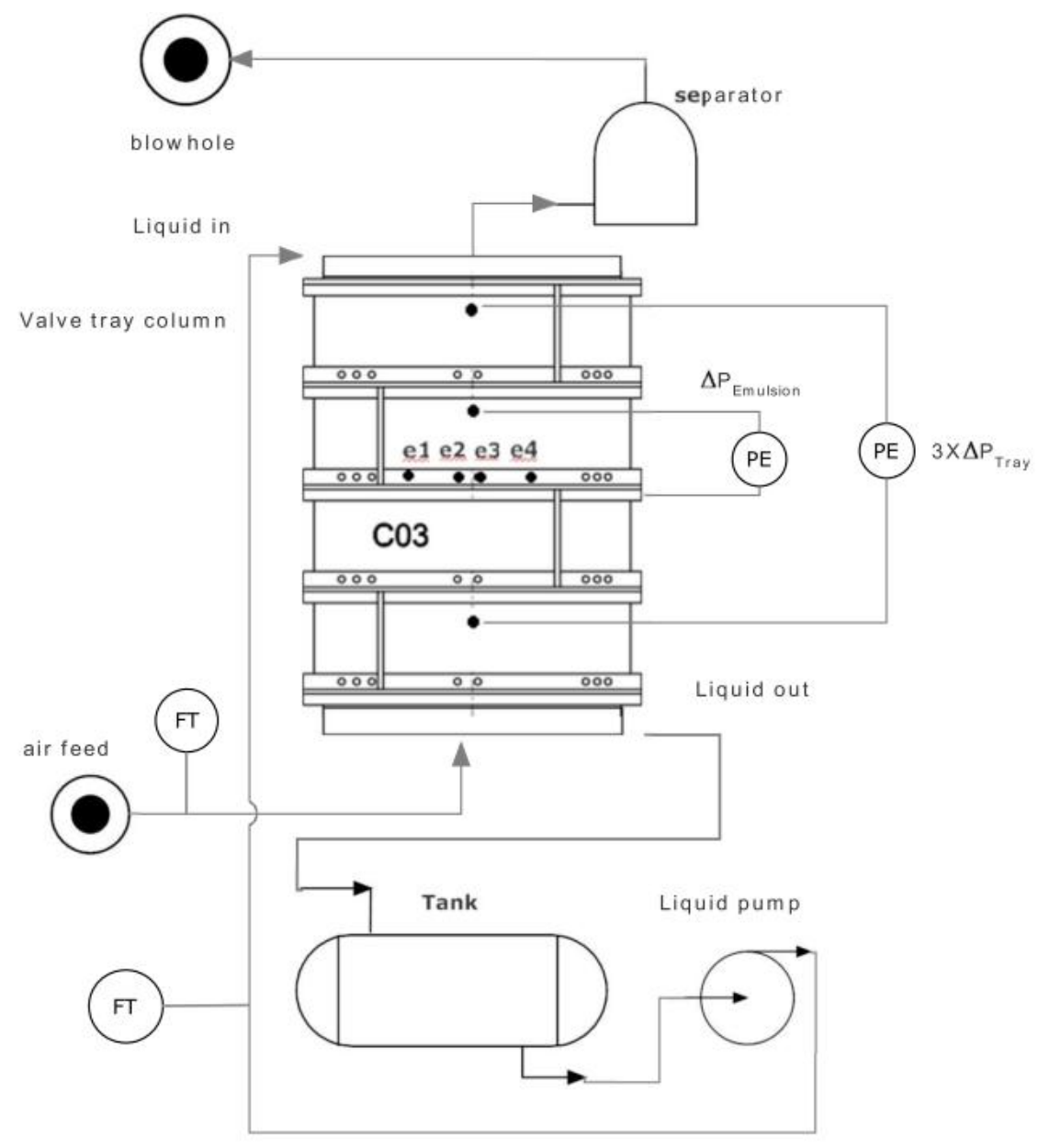

Figure 1 : Sketch of experimental set up schema pressure drop connections.

\subsubsection{Emulsion height}

Emulsion height measurements were made using video records post-processing.

Firstly, each image from the video sequence is extracted. An air-emulsion separation profile is then estimated by image processing methods involving a marker controlled watershed operator (Serra 1988). Two markers are imposed as first line and last line of the image, respectively. Markers are propagated on a topological function calculated from the image by morphological gradient and morphological closing using disk as structuring element (Serra 1988) (cf. figure 2). All these profiles can be used to calculate a probability map indicating the number of times that a profile is at a certain height. From this height probability map, an average air-emulsion separation can be estimated for one condition video. 

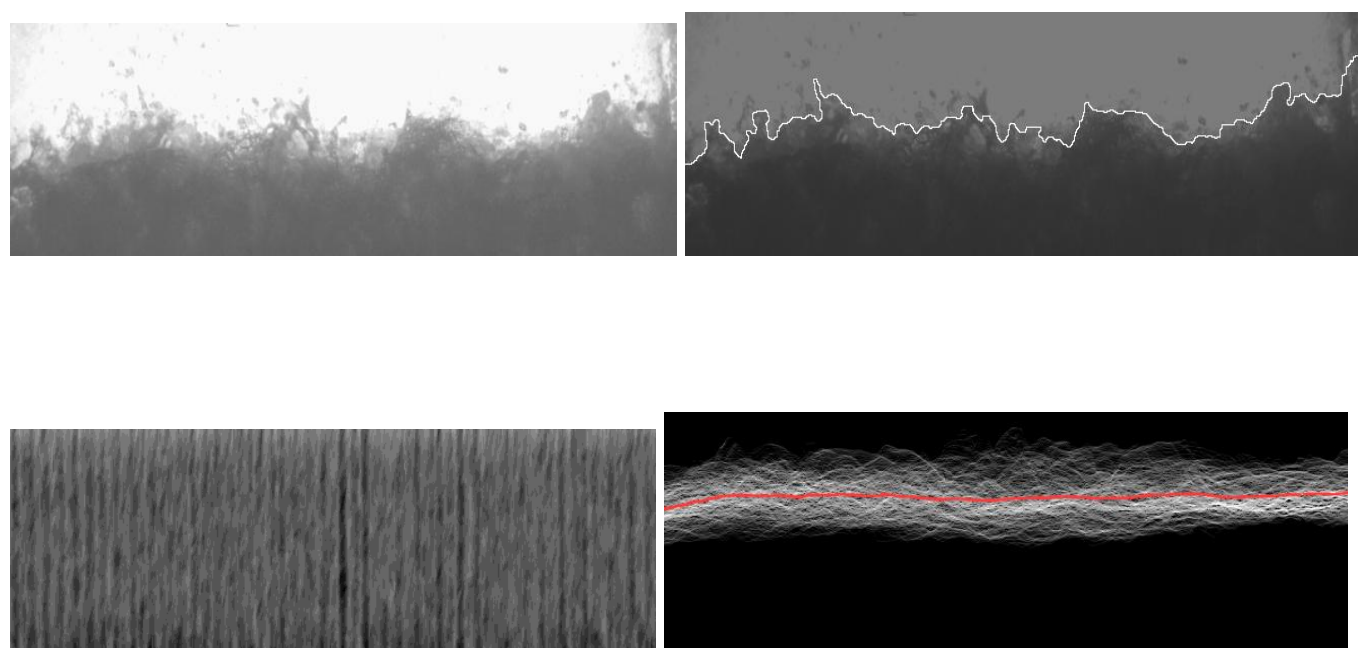

Figure 2 : from left to right and top to bottom: image sequence extracted from a video; airliquid separation profile obtained using morphological operations; concatenation of all profiles of a video ( $x$ axis, $y$ axis and intensity indicating $x$ position on the reactor, time and height of the profile respectively); height profiles probability map and average height profile in colour red.

Quantitative features are then computed from the processed video. These features aim at characterizing the disordered nature of the air-emulsion interface, depending on the input gas and liquid flow parameters. As each video is driven by fixed parameters, the selected features evaluate the deviation from an estimated stationary feature, both in the space and the time directions. The first feature derives from the top right image in Figure 2. It cumulates the standard deviation, over the time slices, of the air-emulsion interface profiles, with respect to an average flat surface. The second feature represents the time-based variation of the profiles, as a mean to evaluate the wavy nature of the bottom left image. 


\section{Results and discussion}

\subsection{Pressure drops}

3.1.1.Dry and valves pressure drops $\left(\Delta P_{\text {Dry }}, \Delta P_{\text {Valves }}\right)$

Three zones characterizing $\Delta P_{\text {Valves }}$ are shown in Figure 3. The first zone corresponds to closed valves. Gas flows through minimum opened surface area and $\Delta P_{\text {Valves }}$ increases linearly with square gas velocity. In this zone, few negative pressure drops can be noticed. The weeping is very important for this range of kinetic gas factor $F a$ and it may explain these values. The second zone corresponds to a stagnation region where valves open progressively. Gas velocity at the orifice is almost constant and this explains the stagnation of pressure drop. This second zone is delimited by the closure balance point $(C B P)$ for which all valves are closed and the open balance point $(O B P)$ for which all valves are opened.

Finally, in the third zone all valves are opened and $\Delta P_{\text {Valves }}$ increases once more with gas velocity.

In absence of liquid flow $\left(L=0 \mathrm{~m}^{3} / \mathrm{m} . \mathrm{s}\right)$ and in theory, dry pressure drop $\Delta P_{D r y}$ in the $3^{\text {rd }}$ zone is supposed to rise as the square of gas velocity (Lockett 1986). Experimentally the power on the velocity is actually found to be equal to 1,7 . Correlation of $\Delta \mathrm{P}_{\text {Dry }}$ with kinetic gas factor could be given as follow:

$$
\Delta P_{D r y}=1.5 \cdot F a^{1.7}
$$

With maximum deviation of $1.5 \%$.

Experimental points published by (El-Azrak 1988) for the same valve kind (Glitsch V-4) show dependence to gas velocity comparable to present results (power $=1,7$ ). The deviation from theoretical dependency to gas velocity was reported by other authors for different valves ((Piqueur \& Verhoeye 1976) with A1 Glitsch and KV Koch valves; (Mustafa \& Békássy-Molnár 1997) with Nutter valves; (Fasesan 1987) with Koch T).

(El-Azrak 1988) and (Piqueur \& Verhoeye 1976) worked on valves similar to those used in this work. Compared to their results the present experimental results show good agreement (Figure 4). 
In presence of liquid flow, dependence on gas velocity after OBP point varies between 1,5 and 1,9. No experimental results were found in literature for comparison. Indeed, in presence of liquid flow, valves pressure drop is usually considered equal to dry pressure drop.

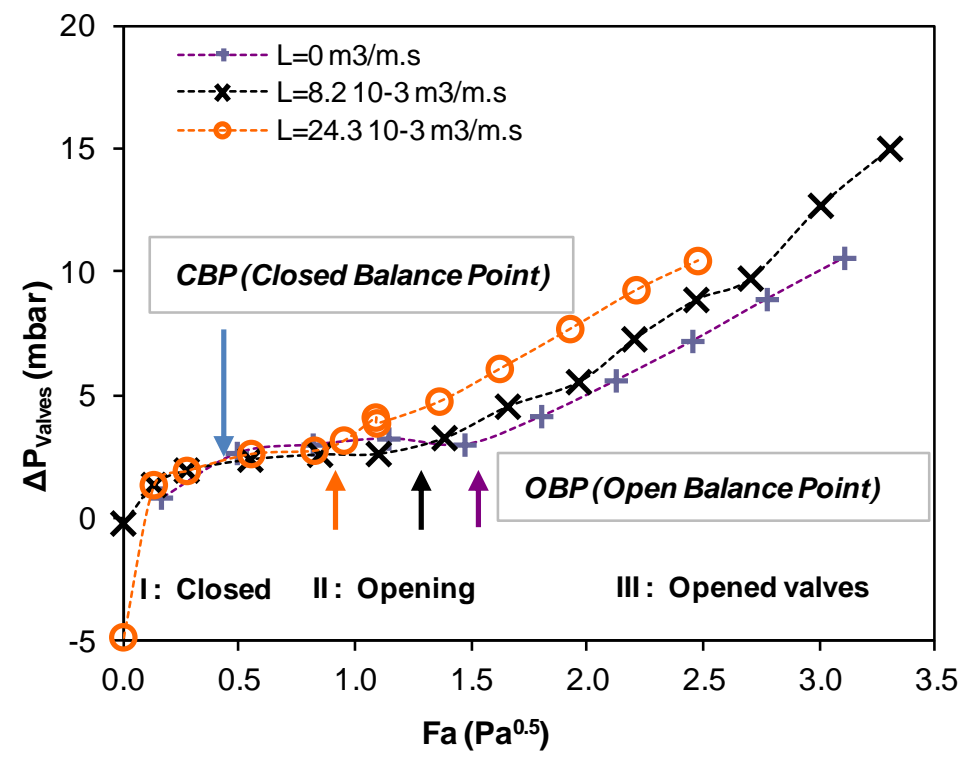

Figure 3 : Valve pressure drop $\Delta P_{\text {Valves }}$ for deferent $L$.

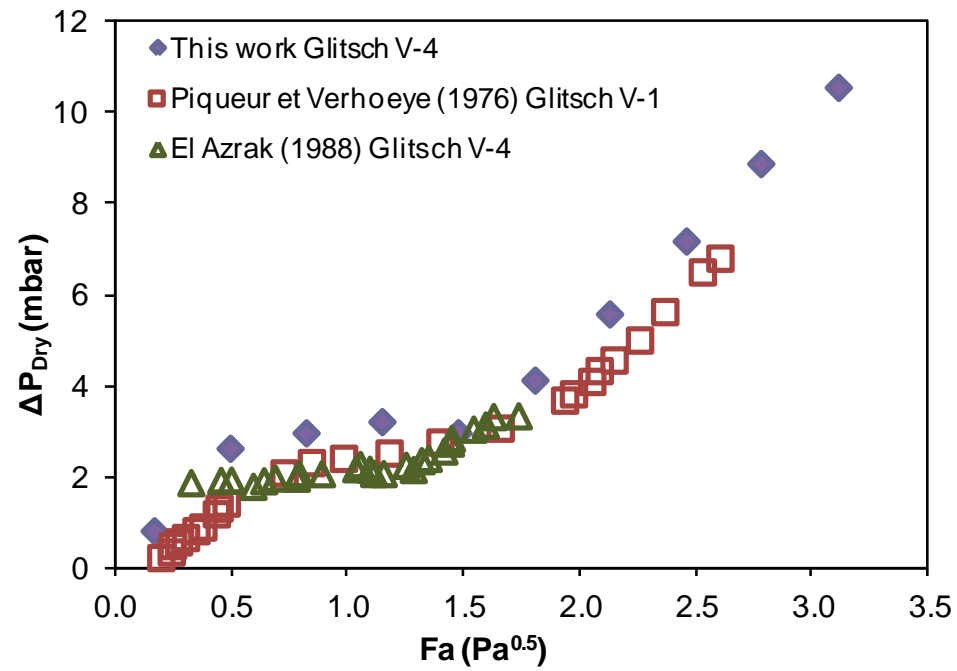

Figure 4 : Dry pressure drop from several experimental studies (see Table 2 for geometrical characteristics of reference works). 
The OBP point is dependent on liquid loading as shown in Figure 3. Increasing liquid velocity on the tray decreases minimum gas rate needed to open all valves. Correlating gas inertia for OBP points with liquid inertia gives the following expression:

$$
F a_{O B P, L}^{2}=2.1-9 \times 10^{-3} \rho_{L} U_{L}^{2}
$$

Where $U_{L}$ is liquid velocity calculated as:

$$
U_{L}=\frac{Q_{L}}{L_{w} \times h_{L c}}
$$

Results of this correlation are presented Figure 5 and provide maximum deviation of $6 \%$.

The depression generated by liquid velocity could so explain the decrease in kinetic gas factor at OBP point. This dynamic effect of liquid flow facilitates valves opening and so helps gas to access the tray.

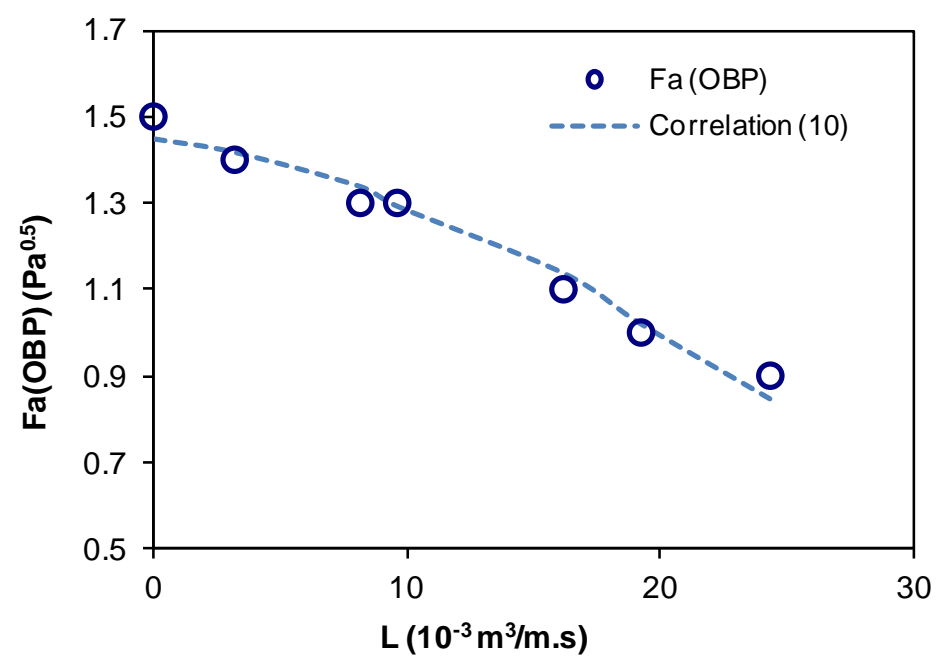

Figure 5 : Dependence of the Open Balance Point (OBP) on liquid load $L$.

\subsubsection{Clear liquid height $h_{L c}$}

From Figure 6, two main zones characterize $h_{L c}$ variation. The first zone, in which $h_{L c}$ rises with increased kinetic gas factor $F a$, corresponds to an important weeping zone, usually called dumping zone. As hole gas velocity increases, it inhibits weeping and clear liquid height on the tray increases consequently until reaching a maximum indicating the dumping zone limit. For higher gas velocities, weeping exists but with a much lower rate than in the dumping zone(James R. Fair 1997) 
The value of kinetic gas factor corresponding to this limit decreases with increased liquid load. This highlights a depression on the tray caused by the increase in liquid velocity. This depression prevents excessive liquid flow through perforations.

In the second zone $h_{L c}$ decreases very slowly until reaching a stagnation plate. Effect of liquid viscosity and gas acceleration which were neglected in emulsion pressure drop could not explain this decrease because both contributions would lead to increase emulsion pressure drop. This behaviour should be explained by the fact high gas velocities on the tray assist liquid evacuation (El-Azrak 1988).

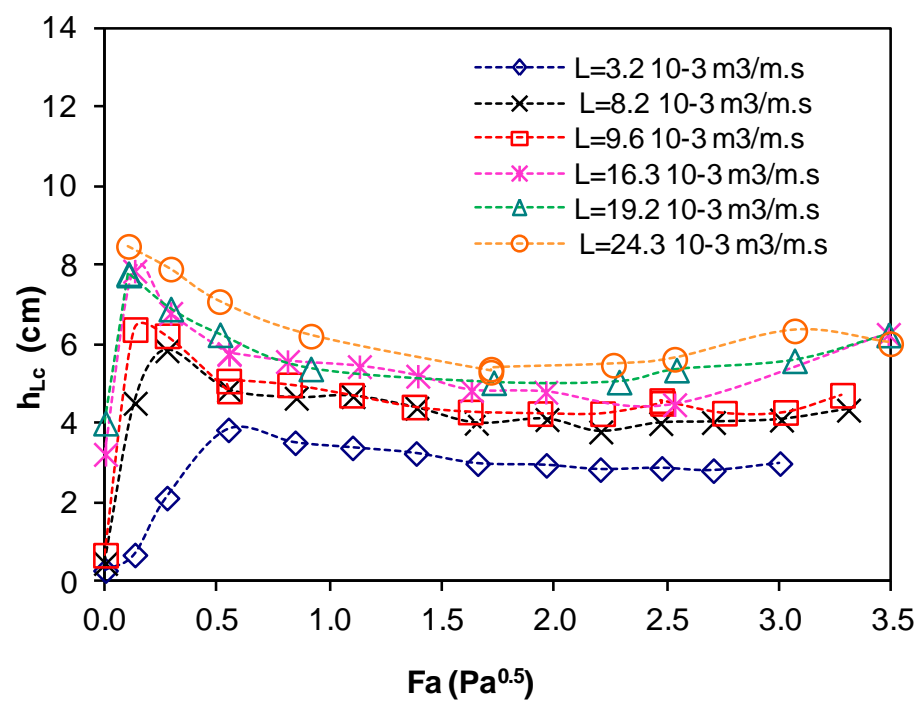

Figure 6 : Clear liquid height $h_{L c}$ for deferent $L$.

Some authors report that clear liquid height has little dependence on valve type ((Liang et al. 2008); (Piqueur \& Verhoeye 1976)). Comparison between experimental data issued from different studies using different valves is then possible. Figure 7 shows results for $L=3.210^{-3} \mathrm{~m}^{3} / \mathrm{m} . \mathrm{s}$ in comparison with results of (Dhulesia 1984), (Fasesan 1987) and (Mustafa \& Békássy-Molnár 1997) on different valve trays. Present results are reasonably in accordance with these references. Because of a larger span of kinetic gas factor tested on this work, the first phase corresponding to weeping range is not reported by those authors. Dependence on $F a$ at fixed liquid rate is comparable between present 
results and those of (Mustafa \& Békássy-Molnár 1997) and those of (Fasesan 1987). However, effect of kinetic gas factor is higher for (Dhulesia 1984) data.

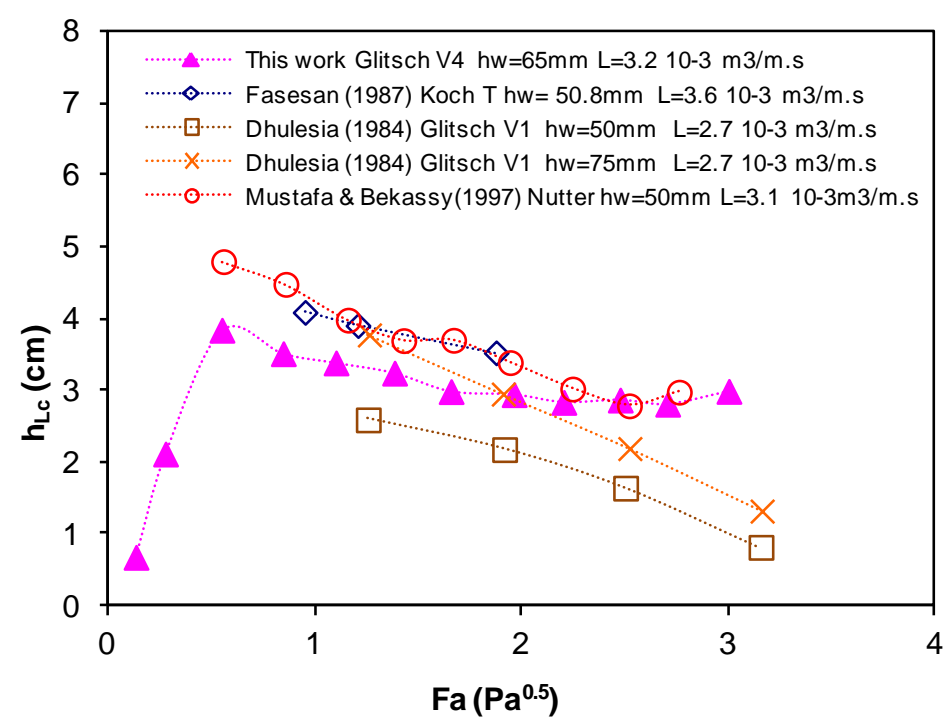

Figure 7 : Comparison between our measurements and literature data.

(Dhulesia 1984) and (Mustafa \& Békássy-Molnár 1997) propose correlations for clear liquid height using flow ratio $\psi$ and weir height $h_{w}$ as parameters.

Flow ratio represents the quotient between liquid load times root square liquid density and kinetic gas factor. Interaction between the two fluids is thus pointed out.

Excluding the first region of dumping, we studied dependency toward the flow ratio $\psi$

$$
h_{L c}=6.3 \times \psi^{0.2}
$$

Maximum deviation is of $20 \%$.

The choice of flow ratio as a correlating parameter for clear liquid height describes conveniently the variation of clear liquid height with both liquid and gas velocities. 


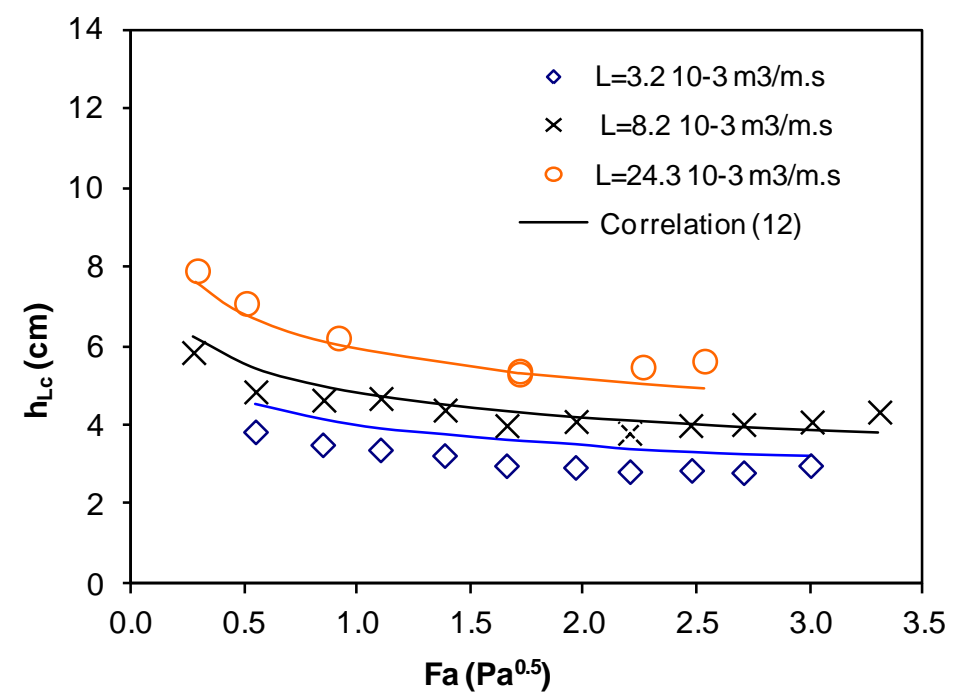

Figure 8 : Clear liquid height correlation in comparison with experimental data.

\subsubsection{Tray pressure drop $\Delta P_{\text {Tray }}$}

Figure 9.a reports tray pressure drop $\Delta P_{\text {Tray }}$ for different liquid loads. Three main phases could be recognised.

The first zone is the dumping zone ending with a local maximum of $\Delta P_{\text {Tray. }}$. The impact of $h_{L c}$ is more important on the total pressure drop compared to the effect of $\Delta P_{\text {Valves }}($ Figure 9.b). The second zone corresponds to a little decrease then a short stagnation zone. As mentioned $\Delta P_{\text {Valves }}$ is stagnant in this region and $h_{L c}$ decreases slightly which explains $\Delta P_{\text {Tray }}$ evolution. In the third zone, $\Delta P_{\text {Valves }}$ becomes predominant and $\Delta P_{\text {Tray }}$ rises sharply. 


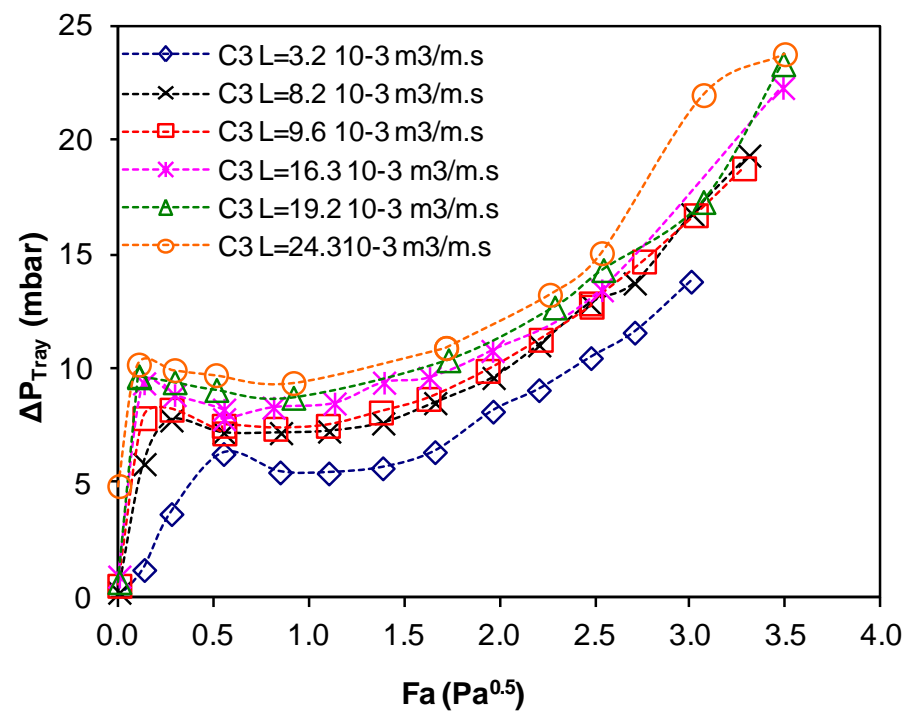

a

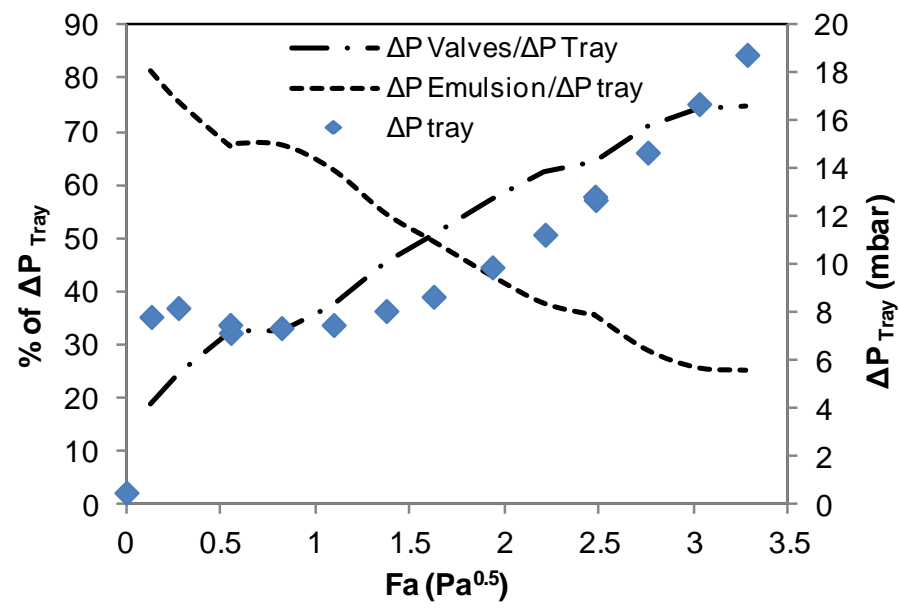

b

Figure 9 : Total tray pressure drop $\Delta P_{T r a y}$ a) for different $L \mathrm{~b}$ ) for $\mathrm{L}=9.6 .10^{-3} \mathrm{~m}^{3} \mathrm{~m}^{-1} \mathrm{~s}^{-1}$ with relative weight of $\Delta P_{\text {Valves }}$ or $\Delta P_{\text {Emulsion }}$ on $\Delta P_{\text {Tray. }}$

\subsection{Emulsion height $\mathrm{h}_{\mathrm{Fe}}$ results}

\subsubsection{Mean emulsion height $h_{F e}$}

Results of mean emulsion height $h_{F e}$ are shown in Figure 10 for different liquid loads.

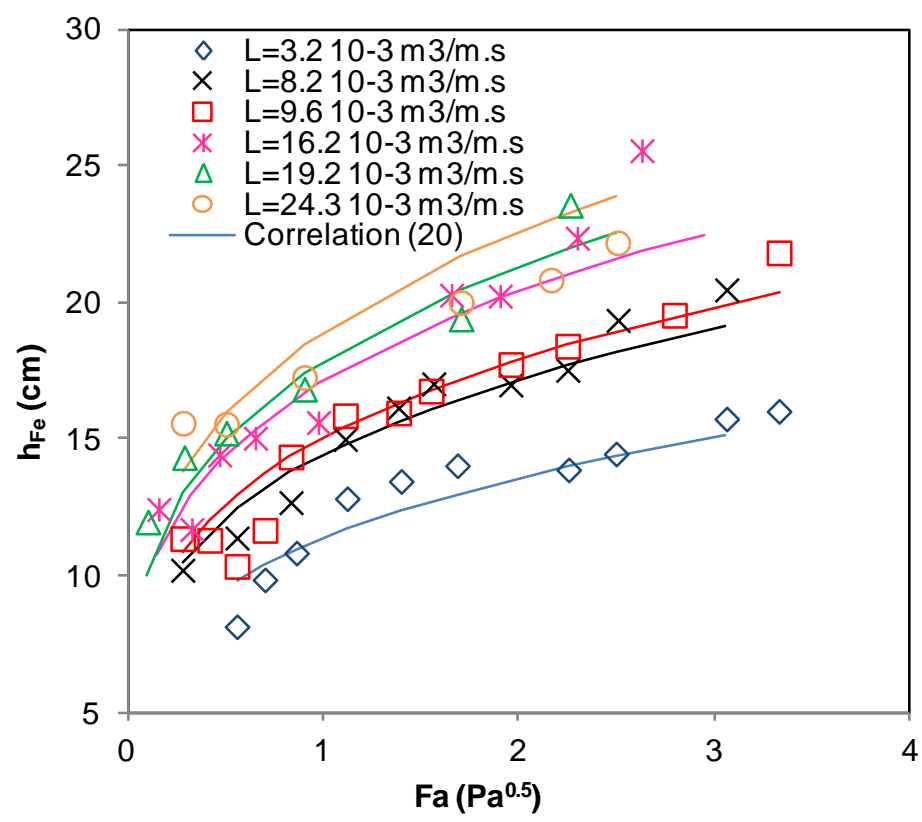

Figure 10 : Mean emulsion height $h_{F e}$ for different $L$. Continuous lines represent correlation 20. 
$h_{F e}$ is an increasing function of both kinetic gas factor $F a$ and liquid load $L$.

Few data is found for mean emulsion height $h_{F e}$ in the literature. In Figure 11 a, the present results for $L=3.210^{-3} \mathrm{~m}^{3} / \mathrm{m} . \mathrm{s}$ are compared to those of (Mustafa \& Békássy-Molnár 1997) at $L=3.110^{-3} \mathrm{~m}^{3} / \mathrm{m} . \mathrm{s}$ and those of (El-Azrak 1988) at $\mathrm{L}=410^{-3} \mathrm{~m}^{3} / \mathrm{m} . \mathrm{s}$ for two different weir heights.

In both reference works, authors measured emulsion height directly on the column using measuring tapes.

As shown in Figure 11 a, present results are reasonably in accordance with those of (Mustafa \& Békássy-Molnár 1997). However, (El-Azrak 1988) data are higher than the present results. This discrepancy is due to the fact he localized maximum emulsion height on trays and not mean height. Considering equally maximum emulsion height, this work results in figure Figure 11.b are in accordance with (El-Azrak 1988) for low kinetic gas factor $F a$. But at higher $F a$ (El-Azrak 1988) reports higher values. The same observation is valid the data of (Mustafa \& Békássy-Molnár 1997). Foaming could be responsible for higher emulsion heights. This phenomenon occurred during the present experiments and anti-foaming agent was used to avoid it. If (El-Azrak 1988) and (Mustafa \& Békássy-Molnár 1997) encountered similar conditions, that could explain the differences in high $F a$. 


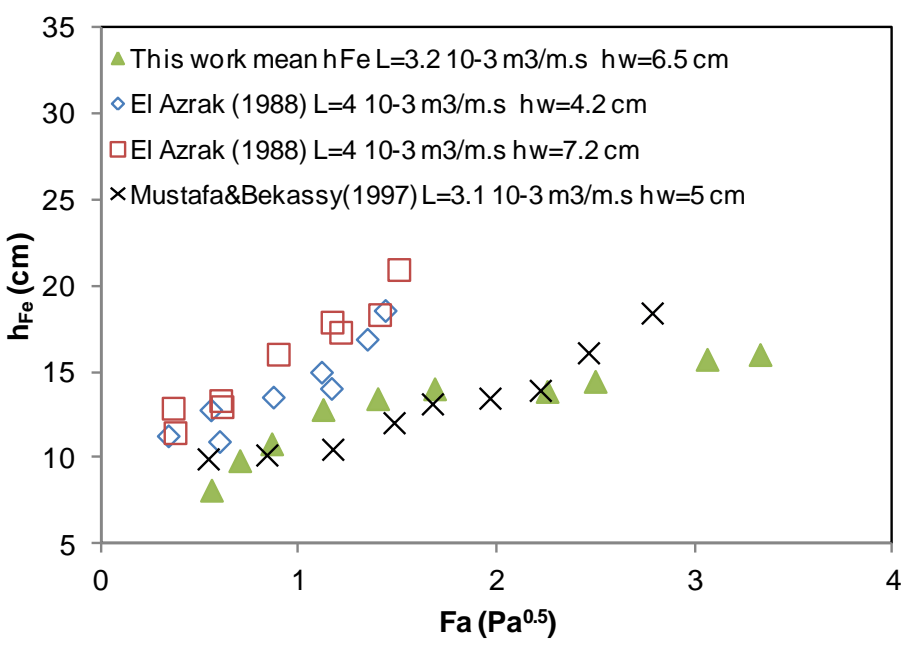

a

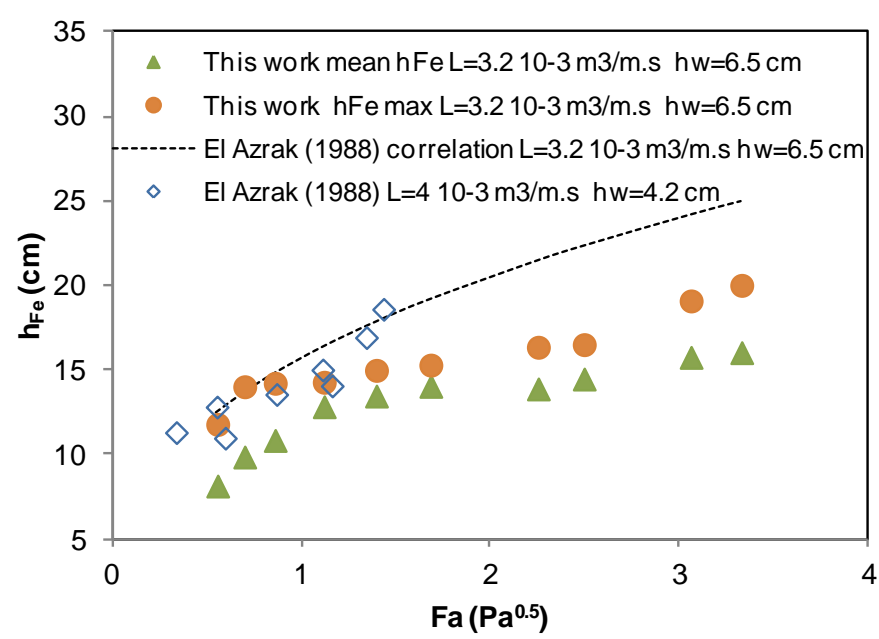

b

Figure 11 : Comparison of mean emulsion height results with literature (a) Comparison to experimental results (b) Comparison to (El-Azrak 1988) maximum emulsion height results.

El Azrak proposed the following correlation:

$$
h_{F e}=0.36 L^{0.06} F a^{0.39} h_{w}^{0.18}
$$

Effect of liquid load, almost inexistent in (El-Azrak 1988) correlation, is found to be important for present experiments while effect of kinetic gas factor is less important than he reported. Actually high dependency toward gas velocity is the result of the pointed out divergence at high $\mathrm{Fa}$. Thus using his correlation, even for maximum emulsion height $h_{F e}$, leads to over estimating emulsion height. (Figure 11.b)

\subsubsection{Emulsion profiles}

Emulsion height is not always homogeneous over the tray. Figure 12 shows an example of profiles evolution for a fixed $L$ and variable $F a$ values. 


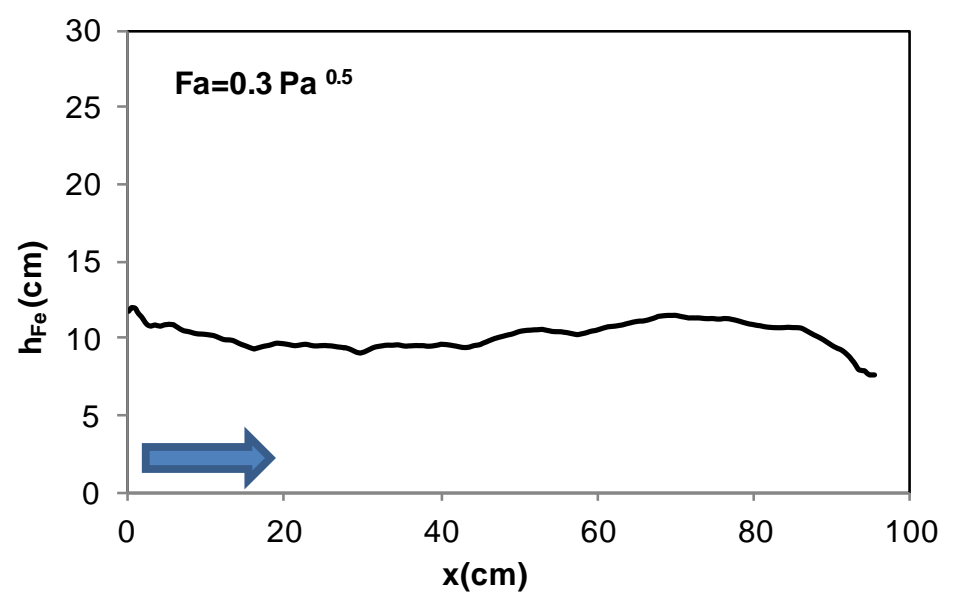

a

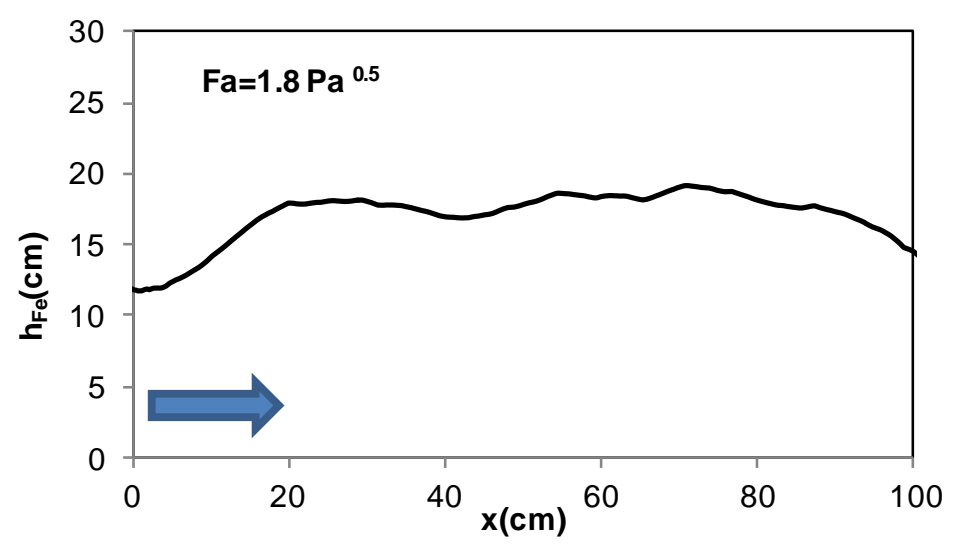

C

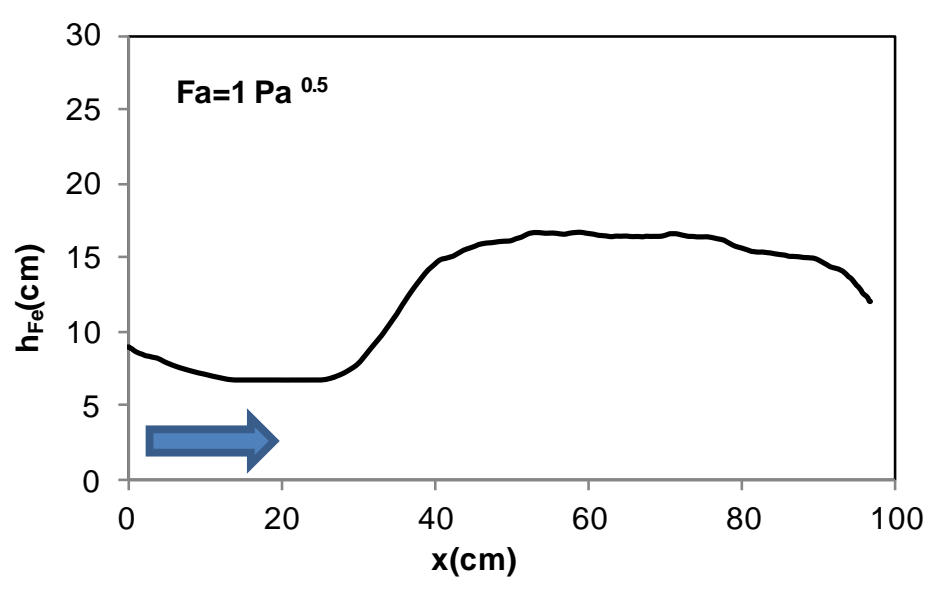

b

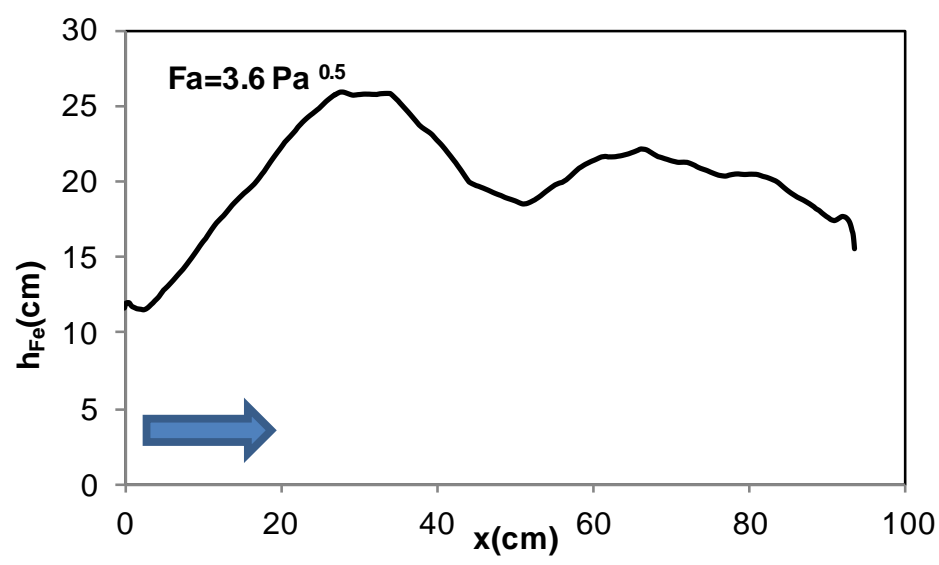

d

Figure 12 : emulsion profiles for $L=8.210^{-3} \mathrm{~m}^{3} / \mathrm{m} . \mathrm{s}$ and different $\mathrm{Fa}$. Blue arrow indicates liquid entrance.

Results of fluctuation criterion are shown Figure 13. For low gas kinetic factors, time fluctuation is remarkably important. This high fluctuation indicates actually weeping regions. Valves at these values of $\mathrm{Fa}$ are oscillating and thus cause fluctuation of emulsion height. 
Flatness deviation criterion in Figure 14 measures deviation of a given profile from the mean emulsion height (deviation from a flat profile). Observing the evolution of this deviation index at a fixed liquid rate reveals four different regions.

Within the weeping domain, two behaviours are recognizable. The first one for very low $F a$ corresponds to little flatness-deviation values. All valves open and close simultaneously leading to a flat mean profile. This corresponds to the dumping domain. (Figure 12.a)

The second weeping region is characterized by important flatness-deviation values. A gas preferential path is established on the tray. Valves are almost totally opened under this preferential path, however the rest of them are oscillating between opening and closure. This domain is the domain between the two limits of weeping. (Figure 12.b)

In the third domain, less deviation is observed and profiles are homogeneous on the tray (except at the entrance and the exit because the influence of entrance clearance and exit weir). (Figure 12.c)

At high $F a$, deviation rises once more indicating the presence of profiles inhomogeneities. These irregularities indicate zones of gas mal-distribution and thus a channelling phenomenon. By increasing further gas rate existing humps rise till reaching the following tray and thus cause flooding.

(Figure 12.d)

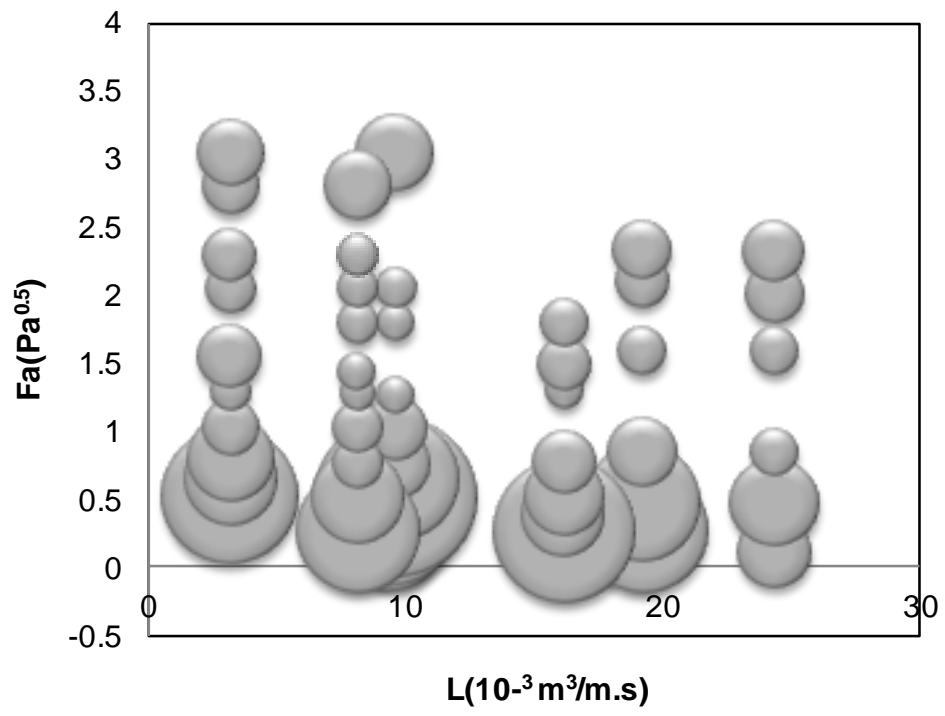

Figure 13 : Average surface fluctuation. 


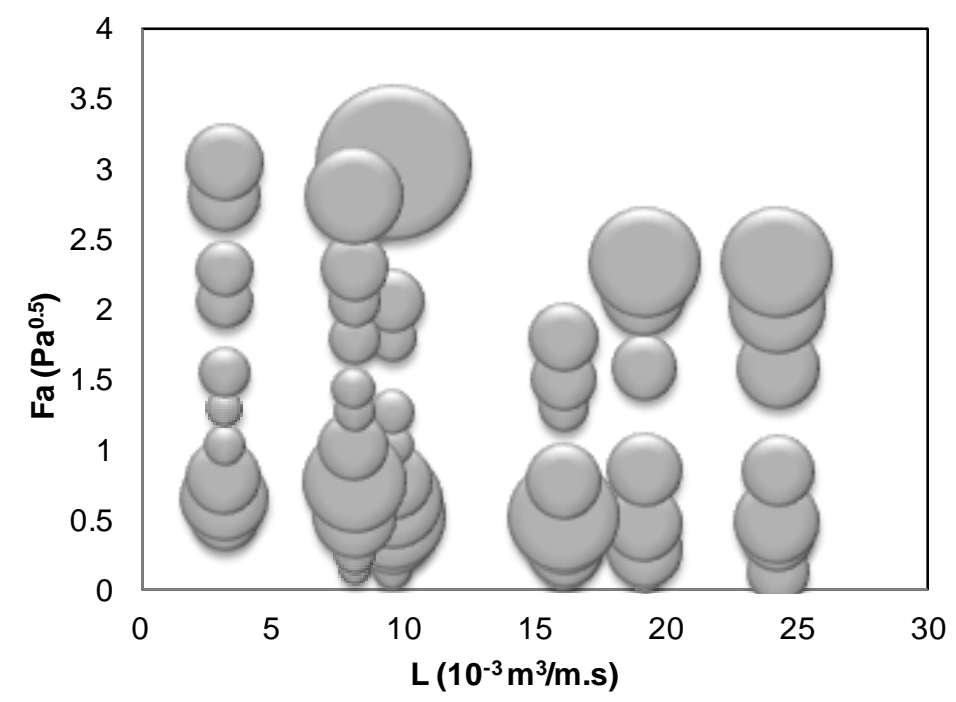

Figure 14 : Average surface flatness deviation.

\subsection{Mean liquid hold up $\alpha_{L}$}

Using $h_{L c}$ and mean emulsion height $h_{F e}$ we measured a mean liquid hold up on the tray $\alpha_{L}$. Results are reported on Figure 15 .

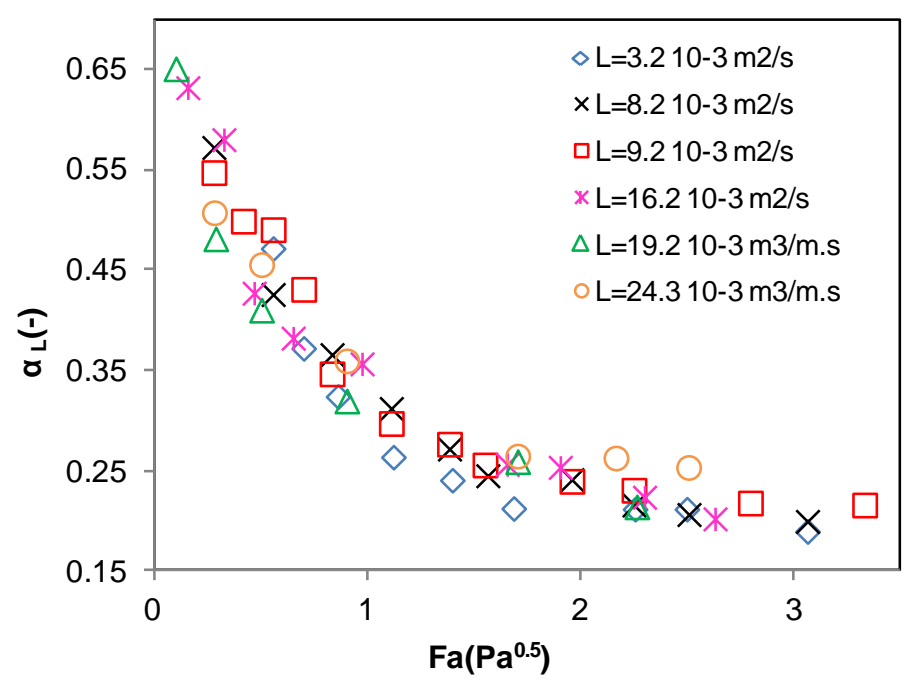

Figure 15 : Mean liquid hold up for different $L$. 
Liquid hold up $\alpha_{L}$ decreases sharply with $F a$ till reaching a saturation phase. Liquid hold up appears to be little dependent on liquid velocity. It is mainly a decreasing function of kinetic gas factor. This observation has been made by several authors. (Bennett et al. 1983) working on sieve trays and (Liang et al. 2008) working on different valve trays propose correlations independent of liquid velocity.

(Bennett et al. 1983)

$\alpha_{L}=\operatorname{Exp}\left[-12.55\left(U_{G, a} \sqrt{\frac{\rho_{G}}{\rho_{L}-\rho_{G}}}\right)^{0.91}\right]$

(Liang et al. 2008)

$$
\alpha_{L}=\frac{1}{1+12.23\left(\frac{A_{\text {slot }}}{A_{a}}\right)^{0.9} F a^{0.61}}
$$

(Colwell 1981) develops a correlation based on Froude number opposing gas kinetic force to liquid weight on tray :

$$
F r=\frac{\rho_{G} U_{G, a}^{2}}{g h_{L c} \rho_{L}}
$$

Using Froude number, Colwell takes into account the effect of liquid rate.

(Colwell 1981) uses a mathematical form suggested for liquid hold up by several works ((Liang et al. 2008); (Lockett 1986)) :

$$
\alpha_{L}=\frac{1}{1+\eta}
$$

$$
\eta=12.6 F r^{0.4}\left(\frac{A_{h}}{A_{a}}\right)^{-0.25}
$$

Figure 16 shows a comparison between these different correlations and present results. The mathematical forma proposed by both Colwell and Liang et al describes better the evolution of liquid hold up. 
Though small, dependence of liquid hold up on liquid rate is not negligible. Thus the choice of Froude number $\mathrm{Fr}$ as correlating parameter seems better suited than using only kinetic gas factor.

Adopting the mathematical forma proposed by both (Colwell 1981) and (Liang et al. 2008), influence of Froude number on liquid hold up is studied. The following correlation is obtained:

$\alpha_{L}=\frac{1}{1+12.28 F r^{0.29}}$

Maximum deviation of this correlation is $16 \%$ and results are reported Figure 16.

Results are comparable to (Colwell 1981) correlation. This latter provides close results to present experimental points. As in this work no variation of perforated area was performed dependency to this parameter could not be verified.

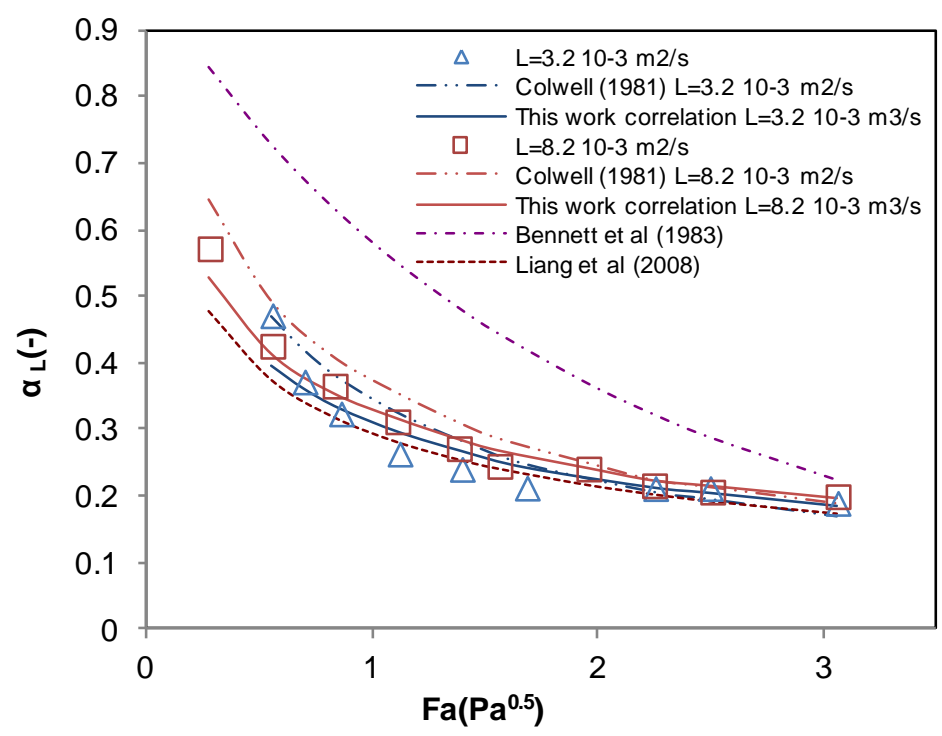

Figure 16 : Liquid hold up correlations.

Using the two correlations proposed for clear liquid height $h_{L c}$ and liquid hold up $\alpha_{L}$ a correlation for mean emulsion height could be proposed as follow:

$h_{F e}=\frac{h_{L c}}{\alpha_{L}}=6.3 \psi^{0.2}\left(1+12.28 F r^{0.29}\right)$

This correlation presents 20\% maximum deviation. (Figure 10) 


\subsection{Operational diagram}

Observing behaviour changes for all preceding results, different system limits are recognized (Figure 17).

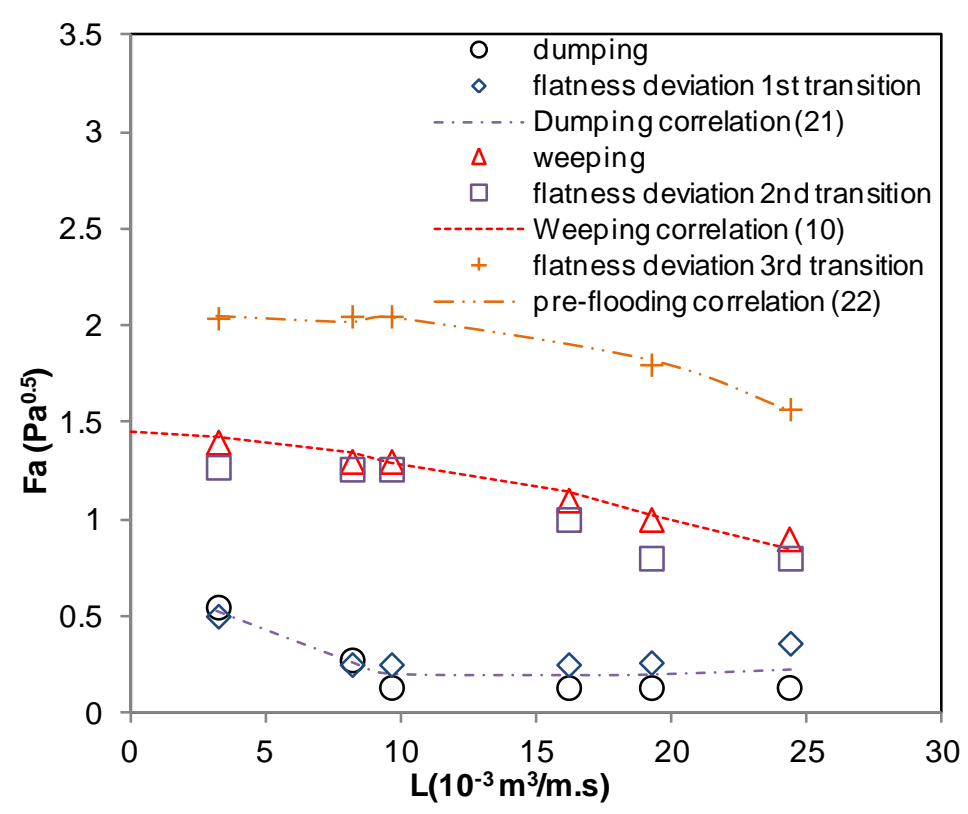

Figure 17 : Experimental system limits.

The first transition corresponds to dumping limit determined according to clear liquid height results. That corresponds also to the first transition identified of flatness deviation feature. When all valves oscillate simultaneously there is alternation between liquid and gas flowing through the tray perforations.

The second limit identified corresponds to open balance point OBP. This limit corresponds as well to the second transition of flatness deviation criterion. It represents the end of valves instability and thus the establishment of a regime of totally opened valves which means little weeping. For this reason this transition is called weeping limit.

(Zanelli \& Del Bianco 1973) studied weeping phenomena (weeping and dumping domains) on perforated trays. They related weeping to oscillations of clear liquid height and gas pressure drop on tray. Oscillations are caused by the competition of liquid weight on the tray with the sum of gas pressure drop and surface tension. Surface tension at the valve hole is negligible in comparison with sieve trays because of much larger hole diameter. Forces in competition in the valve case are liquid 
weight and gas inertia. Therefore, the Froude number is used in most weeping correlations. This dimensional number is used to correlate dumping limit as follow:

$$
F a_{\text {Dumping }}=7.73 F^{0.37}
$$

With maximum deviation of $9 \%$

For weeping limit, corresponding to OBP point, a correlation using liquid inertia has been already introduced:

$F a_{O B P, L}^{2}=2.1-9 \times 10^{-3} \rho_{L} U_{L}^{2}$

Maximum deviation of this correlation is of $6 \%$.

Several correlations for sieve trays weeping exist in literature ((Fair 1997); (Lockett 1986); Mayfield et al 1952); (Wijn 1998)) but hardly any could be found for valve trays.

(Fair 1997) proposed a graphical hydrodynamic diagram for an industrial sieve tray column of $1.52 \mathrm{~m}$ diameter. (Wijn, 1998) proposed a theoretical study of weeping limits for both sieve and valve trays.

Comparison of present dumping and weeping correlations with existing correlations is reported on Figure 18.

The dumping limit is in accordance with (Fair 1997) diagram (Figure 18.a). However present weeping limit shows a different trend from what is proposed in the literature for sieve trays (Figure 18.b). This could be inherent to valve trays which are supposed to lessen weeping phenomena. (Qian et al. 2006) underlined this fact when working on valve trays. Indeed, almost all weeping correlations are based on a critical hole Froude number $F r_{h}$. Presence of the moving valves on the tray and the important difference in hole diameter range compared to perforated plates implies a different critical value of Froude number at the weeping point between valve and sieve trays. Therefore the use of weeping correlations issued from sieve trays works appears to be irrelevant.

(Fair 1997) diagram presents two weeping limits showing dependencies on liquid loading that are opposite. The importance of weeping definition is highlighted since dependency to liquid load depends on weeping relative severity. 
Applying the model proposed by (Wijn 1998) on valve trays to the present clear liquid heights shows a weeping limit that is decreasing with increased liquid loading. The present results are in accordance with this trend though their dependency to liquid loading is higher than the results of (Wijn 1998) model. More experimental data on valve trays is needed for better suited comparison.

The last transition identified in accordance to the emulsion height results is the third transition of flatness deviation criterion. This limit refers to the reappearance of inhomogeneities on emulsion profile due to gas channelling. This is considered here as a pre-flooding limit because further increase of gas velocities leads inhomogeneities to reach upper tray and cause flooding.

Correlation using both Froude number and flow ratio parameters is proposed here for this preflooding limit:

$$
F a_{\text {Pre-flooding }}=75.5 \times \psi^{0.23} F^{0.7}
$$

Maximum deviation is of $2 \%$.

Flooding correlations in literature are available for sieve trays. For valve trays, correlations are usually given by the manufacturers. Some of available correlations are presented in Figure 19. Dependency of pre-flooding correlation on liquid load seems to be comparable to flood correlation trend.

Present experimental results do not allow identifying the effective flooding limit. Actually in the literature, flooding is more usually determined according to entrainment results (Kister and Haas 1988)). 


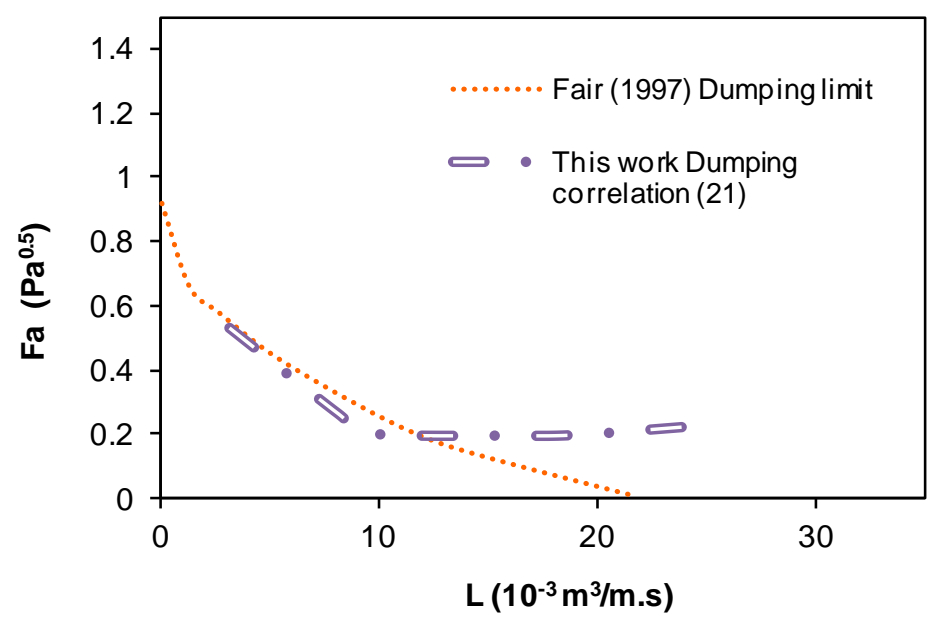

a

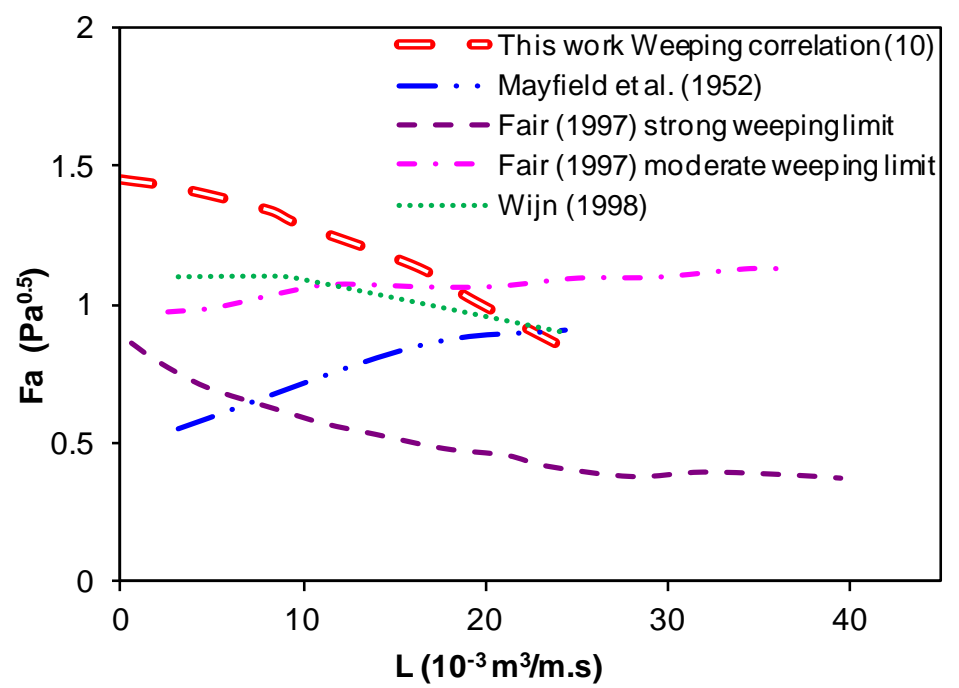

b

Figure 18 : Comparison of present correlations with correlations from literature (a) Dumping

(b) Weeping.

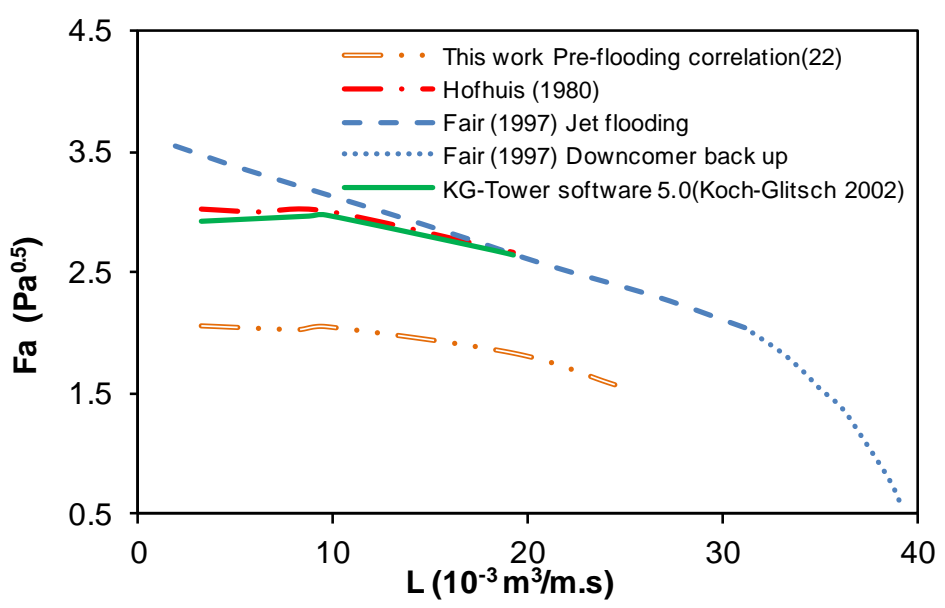

Figure 19 : Comparison of present pre-flooding correlation with flooding correlations from

\section{literature}

\section{Conclusion}

Valve tray absorption columns are commonly used for acid gas treatment process. Few experimental data on pilot units are available which represents a hindrance to optimal design of industrial units. 
In this work, new experimental data for Glitsch V-4 valve trays is reported. Tray and valves pressure drops, clear liquid height, emulsion height and liquid hold up are analysed over a large scope of liquid and gas flow rates. Behaviour changes are observed for these different parameters.

Valves pressure drop results appears to be dependent on liquid velocity. Indeed, valves opening is assisted by the dynamic depression created by liquid velocity on tray. After total valves opening, valves pressure drop increases with gas velocity according to a power less than 2 , the expected value for turbulent flows.

Clear liquid height is determined by emulsion pressure drop. Comparison to literature showed good agreement. A correlation using flow ratio is presented and describes conveniently the variation of $h_{L c}$ with gas and liquid velocities.

Tray pressure drop variations are described in accordance to both valves and emulsion pressure drops. Relative importance of these two parameters controls total tray pressure drop evolution.

Emulsion height measurements are presented with a detailed description of emulsion profile evolution. Emulsion profiles are very little studied in previous works and almost no data exists on valve trays. In the present work, two criteria are identified for quantitative description of emulsion profiles: flatness deviation related to the shape and fluctuation related to evolution in time. Four main domains are identified using these results.

Liquid mean hold up is evaluated and a correlation based on Froude number is proposed.

Defining the different behaviour changes of hydrodynamic parameters and comparing them allows the definition of the system limits : dumping, weeping and pre-flooding. An operational diagram is proposed with correlations of the identified 3 limits.

This diagram can be improved by the determination of the upper system limit (flooding) and regime transitions (emulsion, mixed and spray regimes). In order to do that other experimental measurements are needed (e.g.: entrainment measurements).

Based on such diagram, mass transfer coefficients can be investigated and column design optimization considered with less uncertainties. 


\section{References}

Bennett, D.L., Agrawal, R., Cook, P.J., 1983. New pressure drop correlation for sieve tray distillation columns. AIChE Journal, 29(3), pp.434-442.

Colwell, C.J., 1981. Clear liquid height and Froth Density on seive trays. Ind.Eng.Chem.Process.Des.Dev, 20(2), pp.298-307.

Dhulesia, H., 1984. Clear liquid height on sieve and valve trays. Chemical engineering research \& design, 62(5), pp.321-326.

El-Azrak, A., 1988. Etude des plateaux à clapets - Caractérisation du transfert de matière et de l'hydrodynamique. INP Toulouse.

Fair, James R., 1997. Chapt.13-Distillation and gas absorption, in : Chemical Process Equipment (2005). pp. 397-482 (456).

Fasesan, S., 1987. Hydraulic characteristics of sieve and valve trays. Industrial \& engineering chemistry research, 26(10), pp.2114-2121.

Glitch, Inc., 1974., in : Lockett, M.J., 1986. Distillation tray fundamentals, New York: Cambridge University Press, pp. 89.

Kister, H.Z., Haas, J.R., 1988. Entrainment from sieve trays in the froth regime. Industrial \& Engineering Chemistry Research, 27(12), pp.2331-2341.

Kister, H.Z., Mathias, P.M., Penny, W.R., Crocker, B.B., Fair, J.R., 2007. Equipement for distillation and gas absorption: tray columns. In Perry's Chemical Engineers' Handbook ( $8^{\text {th }}$ edition). 
Koch Engineering Co. 1982, in : Lockett, M.J., 1986. Distillation tray fundamentals, New York: Cambridge University Press, pp. 90.

Liang, Y., Zhou, Z., Shao, M., Geng, J., 2008. The impact of valve tray geometry on the interfacial area of mass transfer. AIChE, 54(6), pp.1470-1477.

Lockett, M.J., 1986. Distillation tray fundamentals, New York: Cambridge University Press.

Mayfield, F.D., Church, W.L., Green, A.C., Lee, D.C., Rassmussen, R.W., 1952. Perforated plate distillation columns. Ind. Engng.Chem., 44(9), p.2238.

Mustafa, H., Békássy-Molnár, E., 1997. Hydrodynamic Characteristics of Nutter Valve Trays, New Correlations. Chemical Engineering Research and Design, 75(6), pp.620-624.

Nutter Engineering Co. 1976, in : Lockett, M.J., 1986. Distillation tray fundamentals, New York: Cambridge University Press, pp. 90.

Piqueur, H., Verhoeye, L., 1976. RESEARCH ON VALVE TRAYS. HYDRAULIC PERFORMANCE IN THE AIR-WATER SYSTEM. Canadian Journal of Chemical Engineering, 54(3), pp.177-184.

Qian, J., Qi, R., Zhu, S., 2006. High-powered adaptative valve tray A new generation tray offers new advantages. Chemical engineering research \& design, 84(A2), pp.155-158.

Wijn, E.F., 1998. On the lower operating range of sieve and valve trays. Chemical Engineering Journal, 70(2), pp.143-155.

Serra, J., Image Analysis and Mathematical Morphology - Vol. II. Theoretical Advances., London, 1988

Zanelli, S., Del Bianco, R., 1973. Perforated Plate Weeping. The Chemical Engineering Journal, 6(3), pp.181-194. 
Zuiderweg, F.J., 1982. Sieve trays: a view on the state of the art. Chemical Engineering Science, 37(9), pp.1441-1464. 